\title{
Effect of intermetallic particles and grain boundaries on short fatigue crack growth behaviour in a cast $\mathrm{Al}-4 \mathrm{Cu}-3 \mathrm{Ni}-0.7 \mathrm{Si}$ piston alloy
}

\author{
T.O. Mbuya ${ }^{\mathrm{a} 1}$, Y. Gu$^{\mathrm{b}}$, R.C. Thomson ${ }^{\mathrm{b}}$ and P.A.S. Reed ${ }^{\mathrm{a}}$ \\ ${ }^{a}$ Engineering Materials Group, Faculty of Engineering and the Environment, Highfield, \\ University of Southampton, SO17 1BJ, UK. \\ ${ }^{b}$ Department of Materials, Loughborough University, Loughborough, LE11 3TU, UK
}

\begin{abstract}
The short fatigue crack growth behaviour in a model cast aluminium piston alloy has been investigated. This has been achieved using a combination of fatigue crack replication methods at various intervals during fatigue testing and post-mortem analysis of crack profiles. Crack-microstructure interactions have been clearly delineated using a combination of optical microscopy, scanning electron microscopy and electron backscatter diffraction. Results show that intermetallic particles play a significant role in determining the crack path and growth rate of short fatigue cracks. It is observed that the growth of short cracks is often retarded or even arrested at intermetallic particles and grain boundaries. Crack deflection at intermetallics and grain boundaries is also frequently observed. These results have been compared with the long crack growth behaviour of the alloy.
\end{abstract}

Keywords Cast aluminium; Fatigue; Micromechanisms of fracture; Piston alloys; Short fatigue cracks.

\section{NOMENCLATURE}

$\begin{array}{ll}\text { 3D } & \text { Three dimensional } \\ a & \text { Crack depth } \\ \text { Al-Si } & \text { Aluminium Silicon } \\ \text { Al0.7Si } & \text { Al-4Cu-3Ni-0.7Si } \\ c & \text { Surface crack length } \\ \text { da/dN } & \text { Crack growth rate (metres per cycle) } \\ \text { EBSD } & \text { Electron backscatter diffraction } \\ \text { EDX } & \text { Energy dispersive X-ray analysis } \\ \text { gbs } & \text { Grain boundaries } \\ \text { HIP } & \text { Hot isostatic pressing } \\ \text { Hipped } & \text { Hot isostatically pressed } \\ \text { SDAS } & \text { Secondary dendrite arm spacing }(\mu \mathrm{m}) \\ \text { SEM } & \text { Scanning electron microscopy } \\ \text { SRCT } & \text { Synchrotron X-ray microtomography } \\ \mathrm{V}_{\mathrm{f}} & \text { Volume fraction }(\%) \\ \Delta \mathrm{K} & \text { Stress intensity factor range }\left(\mathrm{MPa} \cdot \mathrm{m}^{0.5}\right) \\ \Delta \mathrm{K}_{\mathrm{th}} & \text { Threshold stress intensity factor range }\left(\mathrm{MPa} \cdot \mathrm{m}^{0.5} \text { ) }\right. \\ \sigma & \text { Stress (MPa) } \\ \sigma_{\max } & \text { Maximum stress (MPa) }\end{array}$

'Corresponding author. Current contacts and address: Tel. +254 203318262 ext. 28383; E-mail address tmbuya@uonbi.ac.ke; Department of Mechanical and Manufacturing Engineering, University of Nairobi, P.O. 30197, 00100 (GPO), Nairobi, Kenya. 


$\begin{array}{ll}\sigma_{0.2} & 0.2 \% \text { proof stress }(\mathrm{MPa}) \\ \varepsilon & \text { Strain } \\ L_{3} & \text { Particle mean intercept distance, }(\mu \mathrm{m}) \\ \lambda & \text { Mean free distance }(\mu \mathrm{m})\end{array}$

\section{INTRODUCTION}

Al-Si alloys of eutectic or near eutectic composition are commonly used in automotive engine pistons mainly because of the requirement for high castability, low coefficient of thermal expansion and an optimum combination of other desirable properties such as wear resistance and thermal conductivity. ${ }^{1-4}$ The high temperature strength requirement for piston alloys is achieved by increased $\mathrm{Cu}, \mathrm{Mg}$ and $\mathrm{Ni}$ contents in the alloy. Together with $\mathrm{Si}$, these elements improve the strength of these alloys through a combination of solid solution, precipitation and particulate strengthening. Copper contents of between 1 to $4 \mathrm{wt} \%$ are usually specified and form the $\theta^{\prime}-\mathrm{Al}_{2} \mathrm{Cu}$ and also $\mathrm{S}^{\prime}-\mathrm{Al}_{2} \mathrm{CuMg}$ strengthening phases by combining with $\mathrm{Al}$ and $\mathrm{Mg}$. However, at peak piston service temperatures, these phases rapidly coarsen and form the non-coherent $\theta-\mathrm{Al}_{2} \mathrm{Cu}$ and $\mathrm{S}-\mathrm{Al}_{2} \mathrm{CuMg}$ phases with accompanying loss of strength and dimensional stability. ${ }^{3,5,6}$ It has been suggested ${ }^{5}$ that these strengthening phases can be stabilised by using a $\mathrm{Cu} / \mathrm{Mg}$ ratio (by wt.\%) of about 4 to 15 with $\mathrm{Mg}$ not being less than $0.5 \mathrm{wt} . \%$. However, the addition of $\mathrm{Ni}$ at levels between 0.5 and 3 wt.\% forms various strengthening $\mathrm{Ni}$-containing phases such as $\mathrm{Al}_{3} \mathrm{Ni}$ and $\mathrm{Al}_{3} \mathrm{Ni}_{2}$ that are exceptionally stable at high temperature. ${ }^{5}$ Increasing both $\mathrm{Cu}$ and $\mathrm{Ni}$ results in thermally stable $\mathrm{AlCuNi}$ type strengthening intermetallics (e.g. $\mathrm{Al}_{3}(\mathrm{NiCu})_{2}$ and $\mathrm{Al}_{7} \mathrm{Cu}_{4} \mathrm{Ni}$ phases). ${ }^{6,7}$ Nickel also combines with $\mathrm{Fe}$ to form $\mathrm{FeNiAl}$ type phases (e.g. $\mathrm{Al}_{9} \mathrm{FeNi}$ ) that are also stable at high temperature and provide further strengthening. ${ }^{5}$ Moreover, the formation of $\mathrm{Si}$ precipitates in these alloys is also expected to provide additional strengthening. ${ }^{8,9}$

There has been a steady increase in engine performance accompanied with requirements for increased system efficiency, minimum weight and more stringent emission legislation. ${ }^{10}$ This has necessitated intensive research and development of new piston designs and materials that can withstand the increasingly harsh combination of thermo-mechanical fatigue (TMF) and high-cycle fatigue (HCF) loads. ${ }^{2,10-14}$ Recent investigations are looking at increasing the performance of piston alloys by further increasing the $\mathrm{Cu}$ and $\mathrm{Ni}$ contents and increasing the $\mathrm{Si}$ level above the eutectic although there are concerns about reductions in castability. ${ }^{5}$ The aim of these developments has been to achieve maximum performance at high temperatures of $350{ }^{\circ} \mathrm{C}$ and above. ${ }^{5} \mathrm{~A}$ recent research reports indicate alloys with high levels of alloying elements such as $\mathrm{Cu}$ to $\sim 4-6$ wt. \% and Ni to $~ 3.5$ wt. \%. ${ }^{15,16}$ Moreover, Chen ${ }^{17}$ has proposed that $\mathrm{Si}$ be increased to hypereutectic levels although other researchers suggest that $\mathrm{Si}$ be reduced to $<\sim 1 \mathrm{wt}$. \% due to observations that the large blocky primary Si particles in the eutectic or near-eutectic alloys are potent fatigue crack initiators. ${ }^{18,19}$ These low Si alloys are comparable to Al-Cu based alloys such as the 242 alloy that is also used in certain piston applications. ${ }^{20}$ Small additions of $\mathrm{Ti}, \mathrm{V}$ and $\mathrm{Zr}$ have also been suggested to further improve high temperature strength. ${ }^{2,5}$ These elements form compounds of the $\mathrm{Al}_{3} \mathrm{X}$ type $(\mathrm{X}=\mathrm{Ti}, \mathrm{V}, \mathrm{Zr})$ which are stable and coherent with the $\alpha$-Al matrix and, as such, impart high temperature strength and creep properties. ${ }^{21,22}$ These particles also act as grain refiners for $\alpha$-Al primary dendrites. $^{2}$

Piston alloys have a complex three-dimensionally (3D) interconnected microstructure comprising of $\alpha$-Al primary dendrites, various types of intermetallics and Si particles (both primary and eutectic except for the low $\mathrm{Si}$ alloys). ${ }^{23,24}$ In addition to $\mathrm{AlNi}$, AlNiCu, and 
AlFeNi phases discussed above, studies ${ }^{1,17,25,26}$ show that several other phases can occur such as $\mathrm{Al}_{7} \mathrm{Cu}_{2} \mathrm{Fe}, \mathrm{Al}_{2} \mathrm{Cu}, \beta-\mathrm{Al}_{5} \mathrm{FeSi}, \pi-\mathrm{AlFeMgSi}, \mathrm{Mg}_{2} \mathrm{Si}, \alpha-\mathrm{Al}_{15}(\mathrm{Fe}, \mathrm{Mn})_{3} \mathrm{Si}_{2}$ and $\mathrm{Al}_{5} \mathrm{Cu}_{2} \mathrm{Mg}_{8} \mathrm{Si}_{6}$. Significant intermetallic clustering is often observed in some piston alloys. ${ }^{6,13}$ These intermetallics and particularly the large clusters can significantly reduce the alloys resistance to fatigue cracking. ${ }^{15,27}$ Mechanical property characterisation of some of these phases shows that they are significantly stiffer and harder than the $\alpha-\mathrm{Al}$ matrix ${ }^{28}$ and would therefore experience higher stresses during loading due to load partitioning. Like Si particles, these particles are likely to actively participate in fatigue crack initiation and propagation either via interface failure or fracture mechanisms depending on their size, shape and orientation relative to the loading direction. ${ }^{15,29}$

The fatigue performance of aluminium castings is determined by their resistance to the nucleation and growth of fatigue cracks. Either of the two stages can dominate depending on the loading conditions, microstructure and environment. Fatigue cracking in Al-Si castings involves competitive and often synergistic micromechanisms operating at different length scales as influenced by various structural features including defects such as porosity, ${ }^{30-33}$ oxides, ${ }^{33,34}$ surface hollows ${ }^{35,36}$ and corrosion pits. ${ }^{37}$ However, initiation at these features is expected to be preceded by intense localized slip banding. ${ }^{38}$ Local cyclic plastic strains are expected to be even higher at microstructural features such as Si particles, grain boundaries or intermetallic phases which may be located around or near the tips of these defects. ${ }^{39,40}$ Fatigue crack initiation can also occur at individual or clusters of microstructural features such as eutectic Si particles, ${ }^{34,40-43}$ primary Si particles ${ }^{15,19}$ and various types of intermetallic compounds such as $\beta-\mathrm{Al}_{5} \mathrm{FeSi},{ }^{44} \alpha-\mathrm{Al}_{15}(\mathrm{FeMn})_{3} \mathrm{Si}_{2},{ }^{45} \mathrm{Al}_{9} \mathrm{FeNi},{ }^{14}$ and $\mathrm{Al}_{3}(\mathrm{NiCu})_{2} .{ }^{15,19}$ Initiation at these particles can occur either via interface debonding or particle fracture depending on the type of particle, its size, shape and orientation. This may also depend on the loading conditions and the strength of the $\mathrm{Al}$ matrix-particle interface (including the possible presence of precipitate free zones near the interface). ${ }^{38,46}$ Fatigue cracks have also been observed to initiate from persistent slip bands independent of any association with defects or particles. $^{45}$

Short fatigue crack growth in cast Al-Si alloys is significantly sensitive to the local microstructure. It has been observed that short cracks retard and even arrest at microstructural barriers such as grain boundaries, ${ }^{39,47-50}$ eutectic and primary Si particles, ${ }^{19,41}$ intermetallic particles such as $\mathrm{Al}_{3}(\mathrm{Ni}, \mathrm{Cu})_{2}{ }^{51}$ or $\beta-\mathrm{Al}_{5} \mathrm{FeSi}^{44}$ and at interdendritic triple points. ${ }^{42}$ Furthermore, they have also been observed to grow at faster rates than long cracks at equivalent nominal $\Delta \mathrm{K}$ values ${ }^{19,45}$ and even at below the nominal long crack threshold. In the more complex near eutectic Al-Si piston alloys, Joyce et al. ${ }^{19}$ have for example reported classical short fatigue crack behaviour in piston alloys that exhibited crack retardation and/or arrest at primary Si particles. Moreover, from their quantitative analysis of the Si particle sizes, they noted that the crack tended to sample a higher number of Si particles whose mean size was larger than that of the overall population.

Moffat et al. ${ }^{13,15,52}$ recently investigated the model piston alloys shown in Table 1 and observed short crack growth behaviour with frequent retardation and arrest often associated with surface or subsurface intermetallic phases. Furthermore, crack growth was often observed to resume after the phases failed by fracture or debonding. In some cases, secondary cracks reinitiated ahead of the crack tip with intact particles bridging the crack wake before eventually failing as usually observed in fibre reinforced composites. The crack tips were therefore often discontinuous and basically diffuse regions of microdamage and intact ligaments. Significant crack deflections were also observed to occur due to crack interaction 
with second phases although this was not always obvious from two dimensional (2D) surface observations. The authors also observed that the short crack growth behaviour of the low $\mathrm{Si}$ alloy (A10.7Si) was significantly influenced by porosity. ${ }^{13}$ Multiple crack formation at pores and subsequent short crack coalescence was common. Moreover, subsurface cracks associated with porosity were also observed in this alloy using high resolution synchrotron Xray microtomography (SRCT). ${ }^{13}$ Moffat and co-workers confirmed that lowering the level of $\mathrm{Si}$ in piston alloys reduces the role of $\mathrm{Si}$ particles in fatigue crack initiation. However, this is accompanied by increased porosity, which was observed to dominate the initiation and growth of short fatigue cracks particularly in the lowest $\mathrm{Si}$ alloy (Al0.7Si).

Table 1 Compositions (in wt. \%) of the model cast aluminium piston alloys.

\begin{tabular}{lllllllllll}
\hline Alloy & $\mathrm{Si}$ & $\mathrm{Cu}$ & $\mathrm{Ni}$ & $\mathrm{Mg}$ & $\mathrm{Fe}$ & $\mathrm{Mn}$ & $\mathrm{Ti}$ & $\mathrm{Zr}$ & $\mathrm{V}$ & $\mathrm{P}$ \\
\hline Al12.5Si & 12.45 & 3.93 & 2.78 & 0.67 & 0.44 & 0.03 & 0.01 & 0.05 & 0.04 & 0.005 \\
$\mathrm{Al}_{7} \mathrm{Si}^{1}$ & 6.9 & 3.89 & 3.0 & 0.62 & 0.22 & 0.03 & 0.01 & 0.05 & 0.05 & 0.005 \\
$\mathrm{Al0.7 \textrm {Si }}$ & 0.67 & 3.91 & 2.99 & 0.80 & 0.21 & 0.05 & 0.01 & 0.01 & 0.01 & 0.005 \\
\hline
\end{tabular}

${ }^{1}$ This alloy was investigated with and without modification with $\sim 0.015$ wt. \% Sr.

In this work, the low $\mathrm{Si}$ alloy was subjected to hot isostatic pressing (hipped) to reduce porosity to levels that no longer control fatigue failure. This allowed the characterization of the effect of microstructure features on the initiation and growth of short cracks. In this paper, we discuss the results obtained on the short crack behaviour of the hipped Al0.7Si alloy. In particular, a detailed discussion on the effect of grain boundaries (gbs) on the short crack growth behaviour of this alloy is presented. The influence of gbs in retarding and arresting short cracks is well known for the simpler A356 type alloys. ${ }^{39,47}$ To the authors' knowledge, there is no report in the open literature that delineates the effect of gbs on the short crack growth behavior of these more complex multi-component piston alloys. The fatigue crack initiation behaviour of the hipped A10.7Si and Sr-modified A17Si alloys is presented in Mbuya et al. ${ }^{27}$ Moreover, details of the short crack growth behaviour of the hipped Srmodified A17Si alloy is reported elsewhere. ${ }^{53}$

\section{EXPERIMENTS}

\subsection{Materials}

The low Si alloy under investigation was supplied as unfinished pistons (Fig. 1) in the hipped and unhipped conditions. Figure 1 (a) shows the piston casting mould configuration used by the manufacturer to ensure laminar and quiet melt flow conditions during filling ${ }^{54}$. During mould filling, the melt has to pass through a ceramic foam filter before being fed into the die cavity from the bottom. As a result, the melt fills the mould with a slow frontal laminar flow from the bottom while keeping the melt surface undisturbed. This casting process with a ceramic filter and bottom ingate results in a cast structure that is consistently low in oxide inclusions. ${ }^{54}$ The hipped pistons were supplied after being subjected to a hipping and heat treatment procedure involving holding at $490^{\circ} \mathrm{C}$ and $100 \mathrm{MPa}$ for $4 \mathrm{~h}$, solution treatment at $480^{\circ} \mathrm{C}$ for $2 \mathrm{~h}$, a water quench and finally ageing for $8 \mathrm{~h}$ at $230^{\circ} \mathrm{C}$. The unhipped pistons were supplied after aging at $230^{\circ} \mathrm{C}$ for $8 \mathrm{~h}$.

The microstructure of the hipped and unhipped versions of this alloy has been characterized in detail as documented by Moffat ${ }^{13}$ and Mbuya ${ }^{55}$. In summary, a JEOL JSM 6500F scanning electron microscope (SEM) fitted with an Oxford Inca 300 energy dispersive X-ray suite (EDX) was used to identify the phases in the alloys. Quantification of secondary dendrite arm spacing (SDAS), porosity and secondary phases was carried out using 3D SRCT imaging as well as standard 2D stereological methods described by Underwood. ${ }^{56}$ Both optical and 
electron microscopy were used to obtain micrographs for quantitative stereology and measurements were carried out using ImageJ, which is an open source image processing software available at https://imagej.nih.gov/ij/.

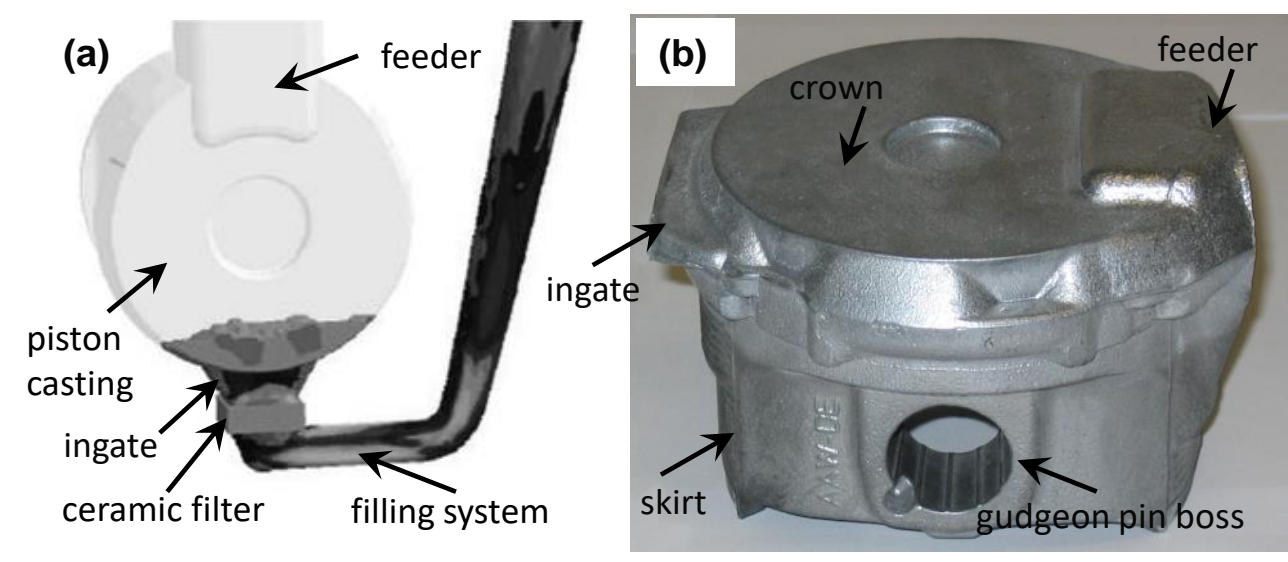

Figure 1 (a) The die cavity and filling system geometry for piston casting and (b) a photograph of a typical unfinished piston as supplied by the manufacturer.

\subsection{Fatigue testing and analysis}

The detailed procedure for specimen preparation, short fatigue crack growth testing and analysis is provided in Mbuya. ${ }^{55}$ However, a summary is provided here for completeness. Tests were performed using $12 \times 12 \times 80 \mathrm{~mm}$ plain bend bar specimens sectioned from the piston crown and overaged at $260^{\circ} \mathrm{C}$ for $100 \mathrm{~h}$ before polishing the top surface to facilitate accurate monitoring of crack initiation and crack-microstructure interactions. The tests were carried out at room temperature using a four point bend loading geometry with a span of 15 $\mathrm{mm}$ on a servohydraulic Instron 8502 machine at a load ratio of 0.1 using a $15 \mathrm{~Hz}$ sinusoidal waveform. With this loading condition, the near-surface tensile region of the specimens was plastically deformed (i.e., above the $0.2 \%$ proof stress $\left(\sigma_{0.2}\right)$ ) although the bulk of the specimen remained elastic. Finite element (FE) calculations were therefore carried out in ABAQUS to determine the stress and strain distributions at the region of maximum bending moment. The maximum top surface stresses were also confirmed by comparing actual strains on the specimen surface (obtained via strain gauges) with the corresponding stress on the tensile stress-strain curve.

The initiation and growth of fatigue cracks was monitored by periodically interrupting the test and taking acetate replicas of the polished tensile top surface of the specimens at the region of maximum stress. This procedure involves softening the surface of a small piece of cellulose acetate with acetone, which is then gently pressed onto the specimen surface and allowed to dry for a few minutes. The acetate replica forms a permanent record of the surface topography of the polished specimen surface, including the crack mouth. This is then analysed in an optical microscope. This method of crack monitoring is discussed in detail by Swain $^{57}$ amongst other crack monitoring techniques described in the same volume.

Three specimens were tested for the hipped alloy at different $\sigma_{\max }$ of $197 \mathrm{MPa}\left(\sim 152 \% \sigma_{0.2}\right)$, $176 \mathrm{MPa}\left(\sim 135 \% \sigma_{0.2}\right)$ and $168 \mathrm{MPa}\left(\sim 129 \% \sigma_{0.2}\right)$. The specimen loaded at $\sigma_{\max }=168 \mathrm{MPa}$ was interrupted after 353000 cycles while the other two were tested to failure after 142967 and 30657 cycles at maximum stresses of 176 and $197 \mathrm{MPa}$, respectively. Moreover a repeat test was carried out for the unhipped alloy at $\sigma_{\max }=138 \mathrm{MPa}\left(\sim 110 \% \sigma_{0.2}\right)$. (Note that the 
stress and strain values for this repeat test were estimated using the strain gauging method). This test was carried out to assess the repeatability of the results reported by Moffat ${ }^{13}$ and therefore provide sufficient confidence for comparison with the results obtained for the hipped alloy investigated in this work. This test was interrupted at 35000 cycles. Table 2 shows all the short crack testing parameters for the hipped and unhipped specimens, including the test carried out in the previous study by Moffat. ${ }^{13}$ Optical images of the cracks on the acetate replicas at various stages of the fatigue loading history were taken and crack length measurements carried out using ImageJ. The crack growth data was then analysed using the secant method to obtain the growth rates $(\mathrm{da} / \mathrm{dN})$ at corresponding $\Delta \mathrm{K}$ values calculated using the solution recommended by Scott and Thorpe. ${ }^{58}$ SRCT analysis of a secondary crack at $\Delta \mathrm{K}=2.5 \mathrm{MPa} \sqrt{\mathrm{m}}$ indicated an $a / c$ ratio of $\sim 0.8$ for the hipped alloy. The differences in the computed values of $\Delta \mathrm{K}$ (for all corresponding measured crack lengths) using $a / c$ ratios of 1 and 0.8 was evaluated and found to be insignificant ( 4\%). The crack shape was therefore approximated to be semi-circular $(a / c=1)$ to allow comparison with previous work by Moffat. ${ }^{13}$ The crack-microstructure interactions were investigated using optical and scanning electron microscopy coupled with phase analysis and grain boundary mapping using EDX and EBSD.

Table 2 Short fatigue crack growth loading conditions and cycles to failure.

\begin{tabular}{lllll}
\hline Alloy (\& Specimen No.) & $\sigma_{\max }(\mathrm{MPa})$ & $\sim N_{i}$ & $N_{f}$ & $\sim N_{i} / N_{f}(\%)$ \\
\hline HIP Al0.7Si (1) & 168 & $<1000$ & 353000 (interrupted) & $<1 \%$ \\
\hline HIP Al0.7Si (2) & 176 & $<1000$ & 142967 & $<1 \%$ \\
\hline HIP Al0.7Si (3) & 197 & $<1000$ & 30567 & $<3 \%$ \\
\hline Al0.7Si (repeat test) & 138 & $<1000$ & 35000 (interrupted) & $<3 \%$ \\
\hline Al0.7Si (ref. $^{13}$ ) & 132 & 2000 & 67580 & $3 \%$ \\
\hline
\end{tabular}

\section{RESULTS}

\subsection{Microstructure}

The phases identified in the hipped alloy using SEM/EDX were $\mathrm{Al}_{3} \mathrm{Ni}, \mathrm{Al}_{3}(\mathrm{NiCu})_{2}$, $\mathrm{Al}_{5} \mathrm{Cu}_{2} \mathrm{Mg}_{8} \mathrm{Si}_{6}$, and oxides as shown in Figure 2. The $\mathrm{Al}_{9} \mathrm{FeNi}$ phase was also identified in other micrographs. ${ }^{55}$ An additional interesting observation in relation to oxide particles is the presence of small particles (bright spots) attached to some of them as shown in Figure 2 (a). It is suggested that these particles are $\mathrm{Al}_{2} \mathrm{Cu}$ phases that find the oxide as a favourable substrate for their nucleation and growth. ${ }^{59}$ However, due to their small size, the identity of these phases can only be confirmed via TEM studies, which was not carried out in the current study.

Chen ${ }^{17}$ has used thermodynamic modelling and EBSD combined with EDX to predict and identify the various phases in the unhipped version of this alloy. The phases predicted to occur using non-equilibrium Scheil simulations include $\mathrm{Al}_{3} \mathrm{Ni}, \mathrm{Al}_{3} \mathrm{Ni}_{2}, \mathrm{Al}_{9} \mathrm{FeNi}, \lambda$ $\mathrm{Al}_{5} \mathrm{Cu}_{2} \mathrm{Mg}_{8} \mathrm{Si}_{6}$ and $\mathrm{Al}_{2} \mathrm{Cu}$ in significant proportions and $\mathrm{Al}_{7} \mathrm{Cu}_{4} \mathrm{Ni}, \mathrm{Al}_{7} \mathrm{Cu}_{2} \mathrm{Fe}, \alpha-\mathrm{AlFeMnSi}$ as well as $\mathrm{Si}$ but in small quantities. Based on these calculations, some $\mathrm{Si}$ particles would therefore be expected in the microstructure of this alloy, albeit in small proportions. The $\mathrm{Al}_{3} \mathrm{Ni}_{2}$ phase is also referred to as $\mathrm{Al}_{3}(\mathrm{NiCu})_{2}$ because it contains $\mathrm{Cu}$ in almost similar atomic proportions to $\mathrm{Ni}$. It is however difficult to differentiate between this phase and $\mathrm{Al}_{7} \mathrm{Cu}_{4} \mathrm{Ni}$ because of their very similar crystal structure. ${ }^{17}$ Chen noted that most of the phases predicted were observed in the unhipped microstructure except for $\mathrm{Si}, \mathrm{Al}_{2} \mathrm{Cu}$ and $\mathrm{Al}_{7} \mathrm{Cu}_{2} \mathrm{Fe}$. It is 
therefore expected that these same phases should still be present in the alloy even after hipping although $\mathrm{Mg}_{2} \mathrm{Si}$ particles may dissolve due to the high hipping and subsequent solution treatment temperatures (i.e., $490^{\circ} \mathrm{C} \& 480^{\circ} \mathrm{C}$ ). Previous reports ${ }^{60,61}$ indicate that $\mathrm{Mg}_{2} \mathrm{Si}$ phases dissolve rapidly (within $1 \mathrm{~h}$ ) during the solution treatment stage of the common A356-type alloys at temperatures of $\sim 540^{\circ} \mathrm{C}$. Considering the amount of $\mathrm{Mg}$ in the alloy $(0.8$ wt.\%) and the dendrite cell size $(30.2 \pm 3.6 \mu \mathrm{m})$, both of which influence the dissolution rates, it would be expected that the $\mathrm{Mg}_{2} \mathrm{Si}$ particles in this alloy could have dissolved after holding it at the high hipping and solution temperatures (i.e., $490^{\circ} \mathrm{C}$ for $4 \mathrm{~h} \& 480^{\circ} \mathrm{C}$ for $2 \mathrm{~h}$ ).
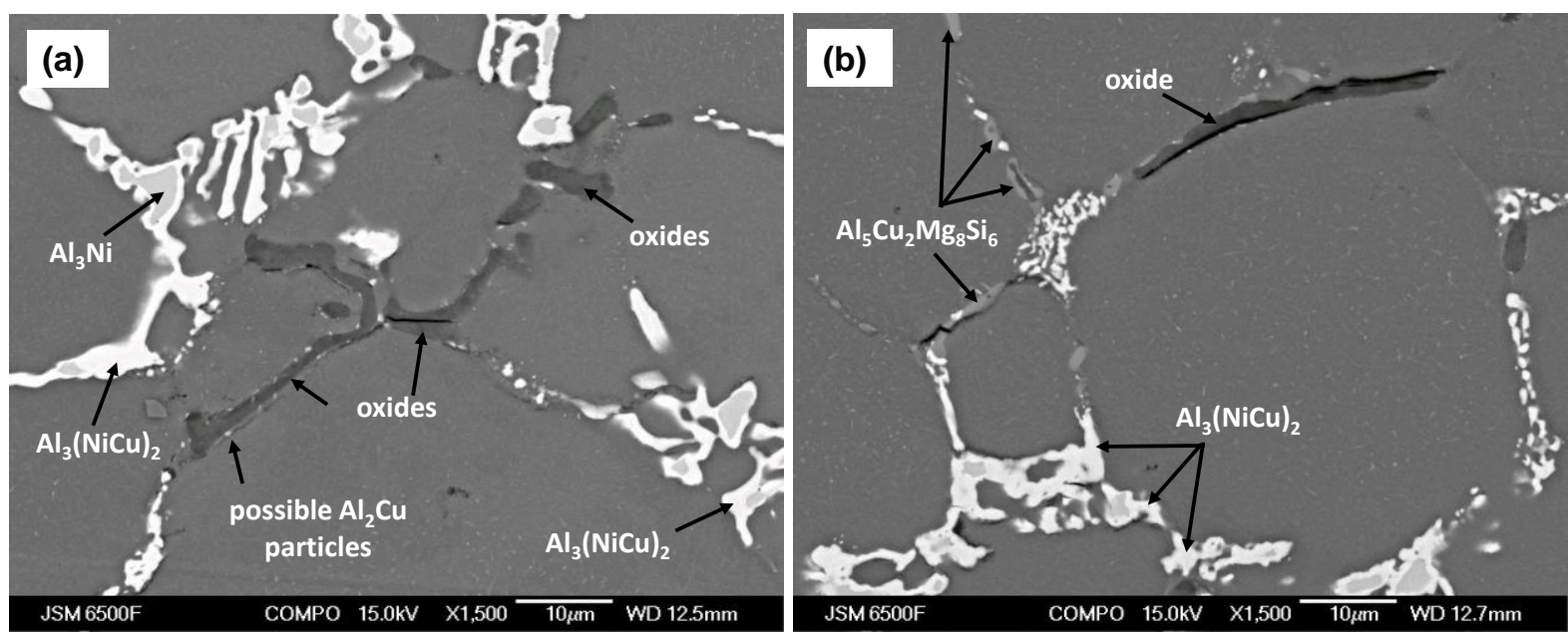

Figure 2 Backscattered SEM images showing the microstructure of the hipped Al0.7Si alloy.

SRCT results shown in Table 3 indicate that hipping does not significantly affect the volume fraction $\left(\mathrm{V}_{\mathrm{f}}\right)$ of intemetallic phases in this alloy, which is $\sim 9.7 \pm 1.6 \%$ as compared to $12.1 \pm$ $2.2 \%$ for the unhipped alloy. The $\mathrm{V}_{\mathrm{f}}$ values are within the standard deviations of each although the hipped alloy has a slightly lower value. Image analysis of backscattered SEM images using ImageJ resulted in a $\mathrm{V}_{\mathrm{f}}$ of $10.5 \pm 3.0$ which makes it difficult to ascertain whether hipping imparted any change in the intermetallic structure. It is however possible that the small amounts of $\mathrm{Mg}_{2} \mathrm{Si}$ particles reported to be present in this alloy could explain the slightly higher value of $\mathrm{V}_{\mathrm{f}}$ in the unhipped version. Such particles would be expected to dissolve in the hipped alloy as already discussed. Furthermore, Scheil simulations by $\mathrm{Chen}^{17}$ suggest a possible presence of $\mathrm{Al}_{2} \mathrm{Cu}$ phases in this alloy. Moreover, $\mathrm{Al}_{5} \mathrm{Cu}_{2} \mathrm{Mg}_{8} \mathrm{Si}_{6}$ phases are confirmed to be present (see Fig. 2(b)). Both these phases are expected to undergo limited dissolution during the hipping and solution treatment stages. ${ }^{62,63}$ It is possible that a combination of these factors could have resulted in a slight reduction in the volume fraction of intermetallic phases in the hipped alloy.

Table 3 Comparison of quantitative stereological data of the unhipped and hipped Al0.7Si alloys.

\begin{tabular}{lll}
\hline & Unhipped Alloy & Hipped Alloy \\
\hline Volume fraction of intermetallics, Vf $(\%)$ & $12.1 \pm 2.2$ & $9.7 \pm 1.6$ \\
\hline Mean free distance, $\lambda(\mu \mathrm{m})$ & $24.9 \pm 6$ & $25.8 \pm 1.9$ \\
\hline Particle mean intercept distance, $L_{3}(\mu \mathrm{m})$ & $3.4 \pm 0.8$ & $3.4 \pm 0.6$ \\
\hline Dendrite arm size, SDAS $(\mu \mathrm{m})$ & $37.3 \pm 10$ & $37.8 \pm 4.1$ \\
\hline Vol. fraction of porosity $(\%)$ & 0.26 & 0.03 \\
\hline Maximum porous region size $(\mu \mathrm{m})$ & 536 & 52 \\
\hline
\end{tabular}

The SDAS is not expected to change during hipping since it is mainly a function of cooling rate. This is confirmed by the SDAS value of $37.8 \pm 4.1 \mu \mathrm{m}$ for the hipped alloy that is 
remarkably close to $37.3 \pm 10 \mu \mathrm{m}$ for the unhipped alloy. It is however clear that hipping significantly reduces both the volume fraction of porosity and the size of the largest pores or porous region, which is particularly important in fatigue failure.

\subsection{Short crack growth data}

The fatigue crack growth data for the hipped and unhipped alloys is presented in Figure 3a. Note that several cracks were analysed for each specimen and one colour has been assigned to the trend lines of all cracks from any given specimen. The data indicates significant scatter in the short crack growth for both the hipped and unhipped alloy, which includes frequent crack growth retardations and even arrest. The figure also shows that the short crack growth rate is generally much higher than the corresponding long crack growth rate for any given value of $\Delta \mathrm{K}$. Moreover, the short cracks grow even at $\Delta \mathrm{K}$ values far below the corresponding $\Delta \mathrm{K}_{\mathrm{th}}$ for long cracks.
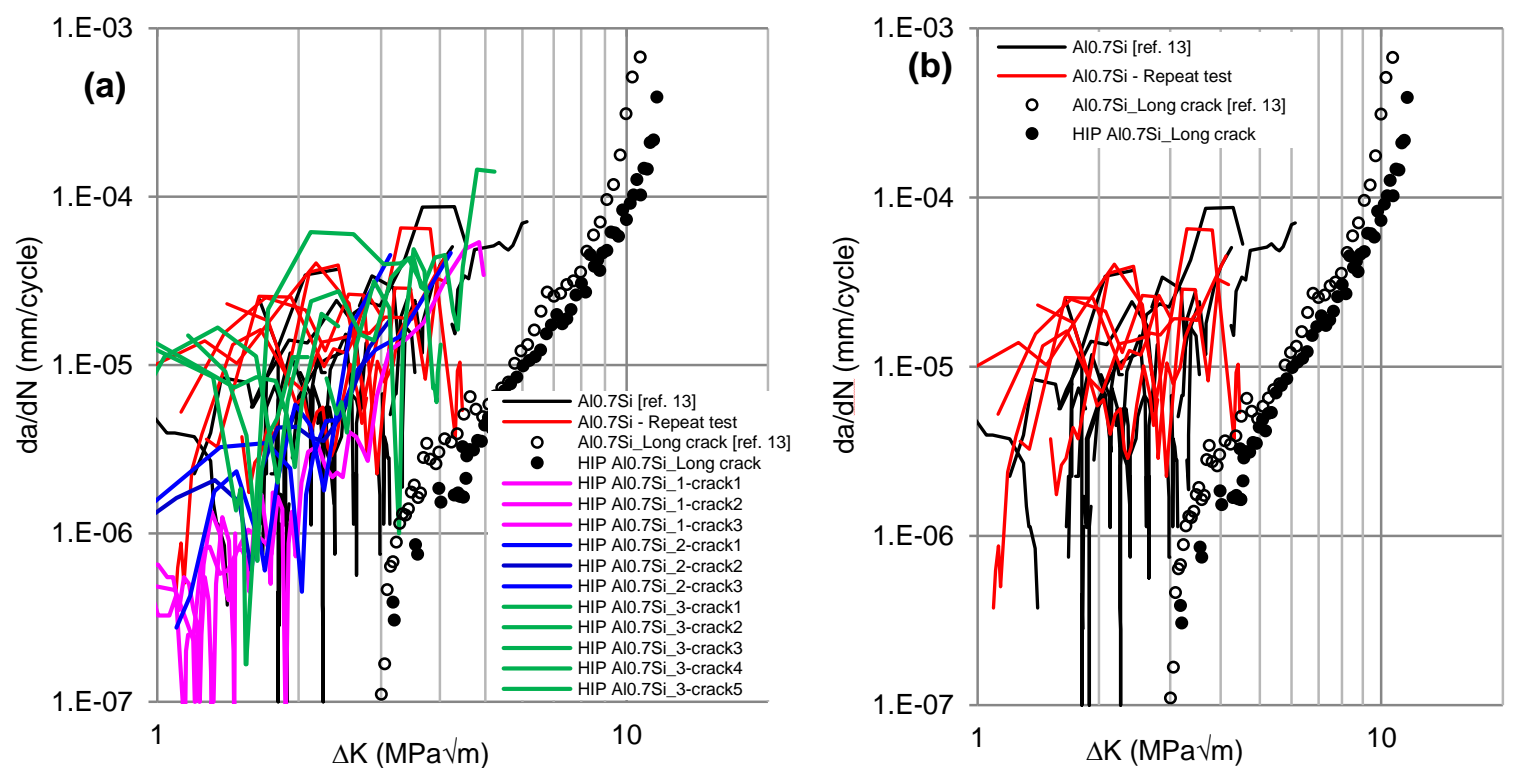

Figure 3(a) Short fatigue crack growth data for the hipped and unhipped Al0.7Si alloy compared with the corresponding long crack growth data. (b) Comparison of repeat test data from the current study to previous results by Moffat ${ }^{13}$ for unhipped Al0.7Si. Note that one colour has been assigned to the trend lines of all cracks from any given specimen. The stress levels associated with each specimen are: $\sigma_{\max }=132 \mathrm{MPa}$ in Moffat's test for unhipped Al0.7Si (in black), $\sigma_{\max }=138 \mathrm{MPa}$ for the repeat test for unhipped Al0.7Si (in red), $\sigma_{\max }=168$ MPa for HIP Al0.7Si_1 (in purple), $\sigma_{\max }=176 \mathrm{MPa}$ for HIP Al0.7Si_2 (in blue) and $\sigma_{\max }=197 \mathrm{MPa}$ for HIP Al0.7Si_3 (in green).

To delineate other short crack growth trends for this alloy, the data in Figure $3 \mathrm{a}$ has been split into several figures. Figure $3 \mathrm{~b}$ shows a comparison of Moffat's ${ }^{13}$ short crack data with results obtained from the repeat test conducted during the current study for the unhipped version of this alloy. It can be seen that the data compares quite well even with the significant scatter observed in both. The only major difference discernible is the slight shift of the lower bound crack growth rates in the repeat test to higher values. The occasional complete crack arrest observed in the previous work was not observed in the repeat test but frequent crack growth retardation events are observed in both. The difference in the lower bound growth rates could be attributed to the slightly higher maximum stress used in the repeat test. Similar stress effects have previously been observed by Caton et al. ${ }^{45}$ in a 319-type cast alloy. More distinct stress effects on short crack growth were observed in the results obtained from the three tests conducted at different stress levels in the hipped version of the alloy as shown in Figure 4a. 
The figure shows that the crack growth rates are generally shifted to higher values with increase in $\sigma_{\max }$ from $168 \mathrm{MPa}$ to $176 \mathrm{MPa}$ and subsequently to $197 \mathrm{MPa}$. Moreover, although complete crack arrest events are observed at the lowest stress, only crack growth retardations are observed in the higher stressed specimens.

The results presented in Figure 3a indicate that hipping improves the resistance to crack growth since the tests on unhipped specimens were carried out at much lower stresses (see Table 2) and yet they exhibit generally higher growth rates. Moreover, the hipped crack growth data in Figure 4a shows a certain level of periodicity in crack growth retardation which is not clearly apparent in the unhipped data presented in Figure $3 b$. This periodicity is shown more clearly in Figure $4 \mathrm{~b}$ in which a few selected curves are presented. What is of most interest is that this periodicity is observed at both tips of the crack analysed for the specimen loaded at $\sigma_{\max }=168 \mathrm{MPa}$. More details on this are provided in Section 3.3.
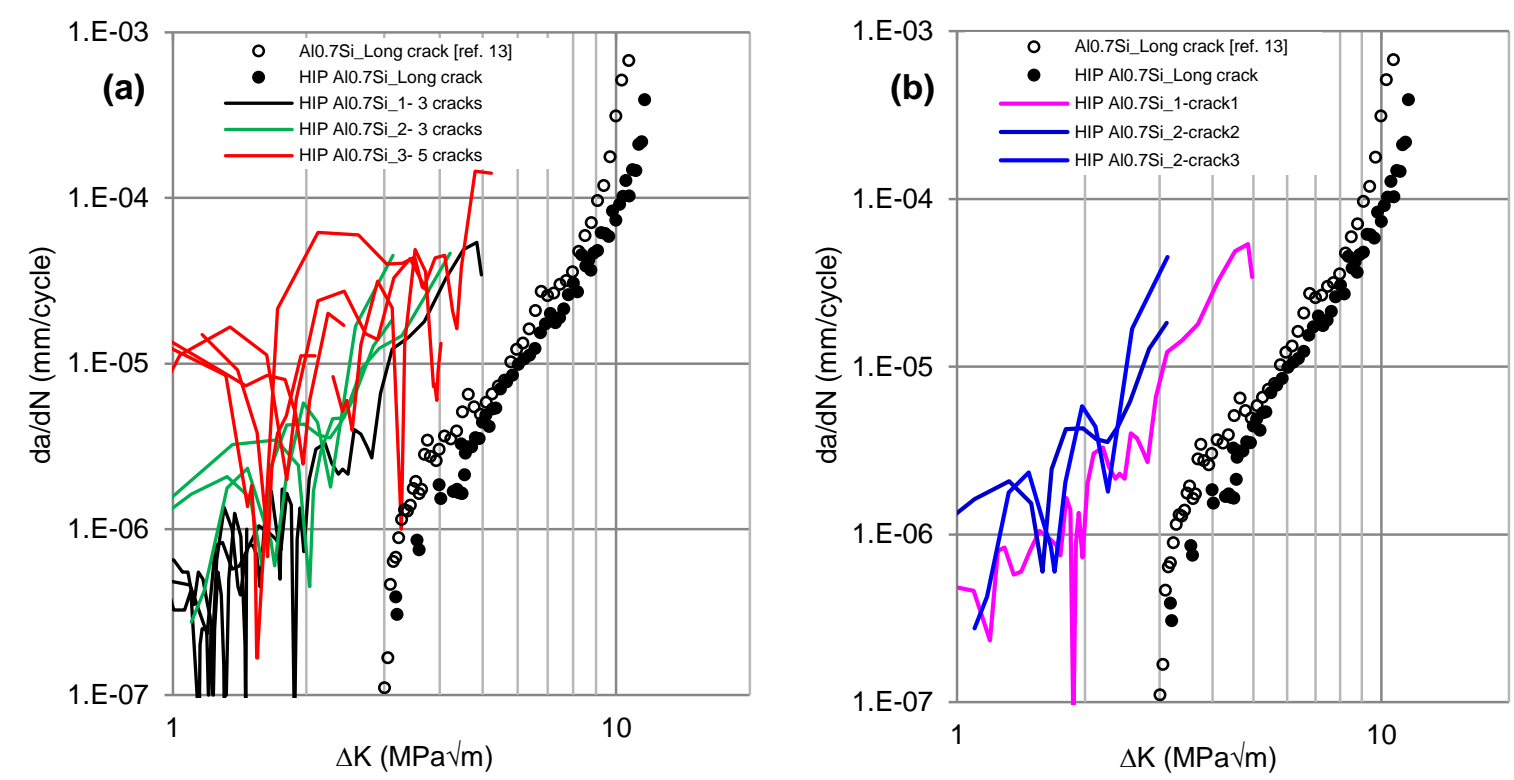

Figure 4 (a) Short fatigue crack growth data for hipped alloy showing the effect of applied stress. $\sigma_{\max }=168$ $\mathrm{MPa}, 176 \mathrm{MPa}$ and $197 \mathrm{MPa}$ for HIP Al0.7Si_1, HIP Al0.7Si_2 and HIP Al0.7Si_3 specimens respectively. (b) Selected short fatigue crack growth data for the hipped alloy showing periodicity in crack growth retardations.

\subsection{Micromechanisms of short crack growth}

Most fatigue cracks observed in the hipped alloys were found to initiate early ( $<1000$ cycles) from either cracked or debonded intermetallic particles except for one case in which a fatigue crack was seen to initiate from a small pore as shown in Figure 5d. This particular specimen was tested at $\sigma_{\max }=197 \mathrm{MPa}$ and exhibited significant crack coalescence. Final failure was due to the coalescence of at least 4 major cracks. For the hipped alloy specimen loaded at $\sigma_{\max }=168 \mathrm{MPa}$, one major crack was thought to have initiated from a debonded intermetallic particle when observed under an optical microscope and SEM as shown in Figure 6. However, EBSD analysis indicated that this crack actually originated from a combined particle debonding and grain boundary decohesion as indicated in Figure 6e. Figure 7 shows that the propagation of one tip (tip A) of this crack is both transgranular and intergranular (Fig. 7c) with significant interaction with intermetallics as shown in Figures $7 \mathrm{a} \& \mathrm{~b}$. It seems that when the crack appears to be interdendritic in Figure $7 \mathrm{a} \& \mathrm{~b}$, it is actually mostly intergranular as shown by the EBSD grain boundary map in Figure 7c. The loading cycles at selected stages of crack growth are indicated along the crack profile in units of 1000 cycles. It 
can be seen that most of the fatigue life is consumed during the early stages of crack growth. Note that crack retardation events can be identified in this figure and are seen to be mainly associated with grain boundaries and intermetallics during the early stages of crack growth (for example, compare $7 \mathrm{a} \& \mathrm{c}$ at about 235000 to 265000 loading cycles).

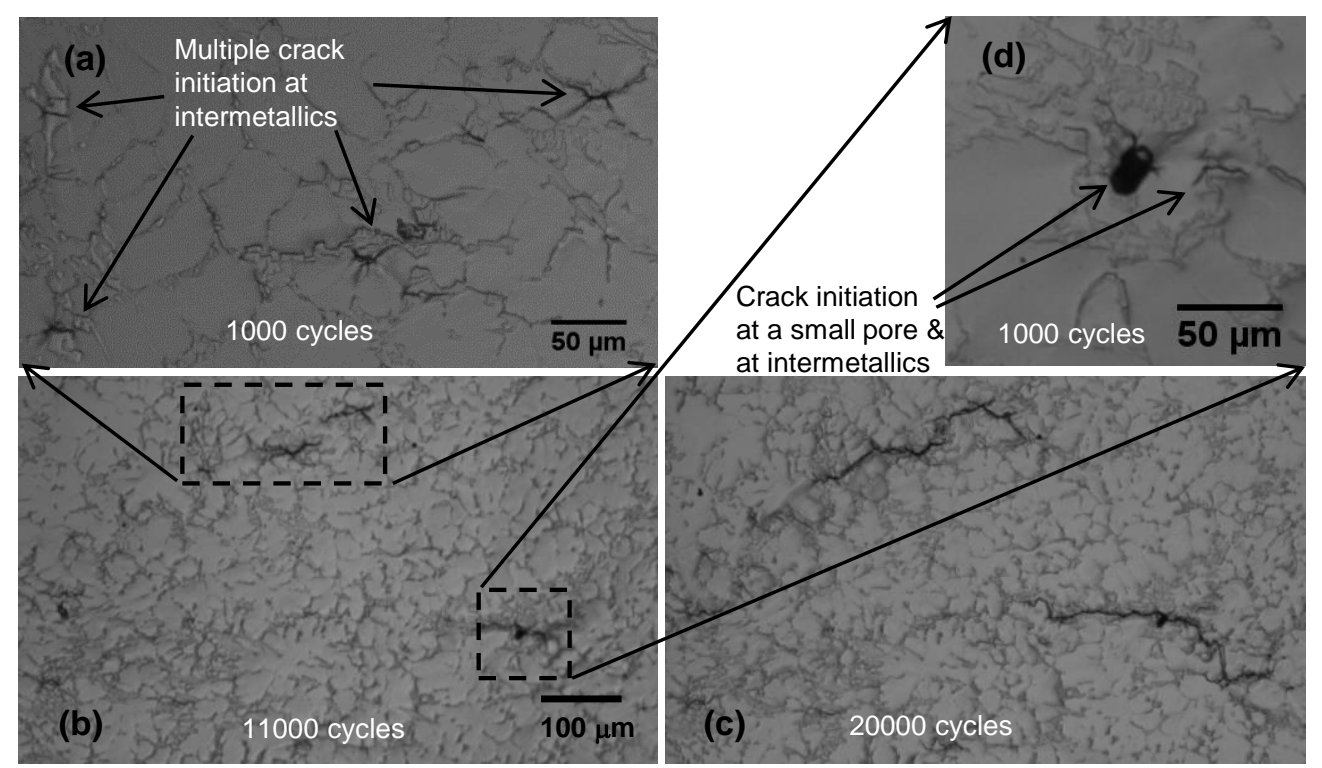

Figure 5 Acetate replica images showing multiple crack initiation sites for the hipped specimen loaded at the highest $\sigma_{\max }(197 \mathrm{MPa})$. Crack initiation was mainly from intermetallics except one case where a crack initiated from a small pore as shown in $(\mathrm{d})$.

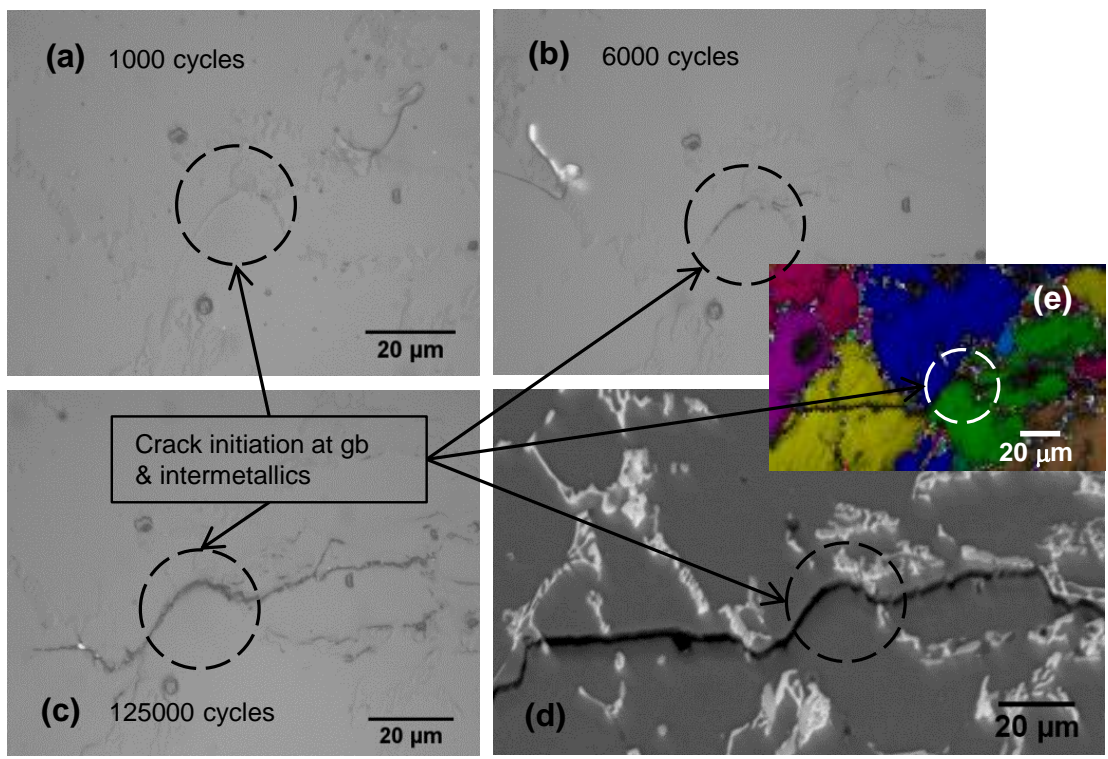

Figure 6 Formation and early growth of a short fatigue crack in the specimen loaded at $\sigma_{\max }=168 \mathrm{MPa}$. Replica images are shown in (a) to (c), an SEM image is shown in (d) and an EBSD grain boundary map in (e).

To explore the crack growth retardation periodicity observed for this crack, the growth rate of individual tips was calculated and presented in terms of the corresponding loading cycles as well as $\Delta \mathrm{K}$ as shown in Figure 8. By comparing the retardation events observed in this figure with the corresponding locations in Figure 7, it can be seen that these are mainly associated with crack interaction with grain boundaries. The interaction of tip B of the same crack with intermetallics and grain boundaries was also investigated and is shown in Figure 9. Crack growth is again observed to be both intergranular and transgranular. However, in this case, 
interdendritic crack growth within individual grains can be observed. By comparing Figure 9 with Figure 10, it can be seen that most retardation events (and therefore the periodicity in growth rates noted in section 3.2) are associated with grain boundaries or intermetallics which are co-located with grain boundaries.

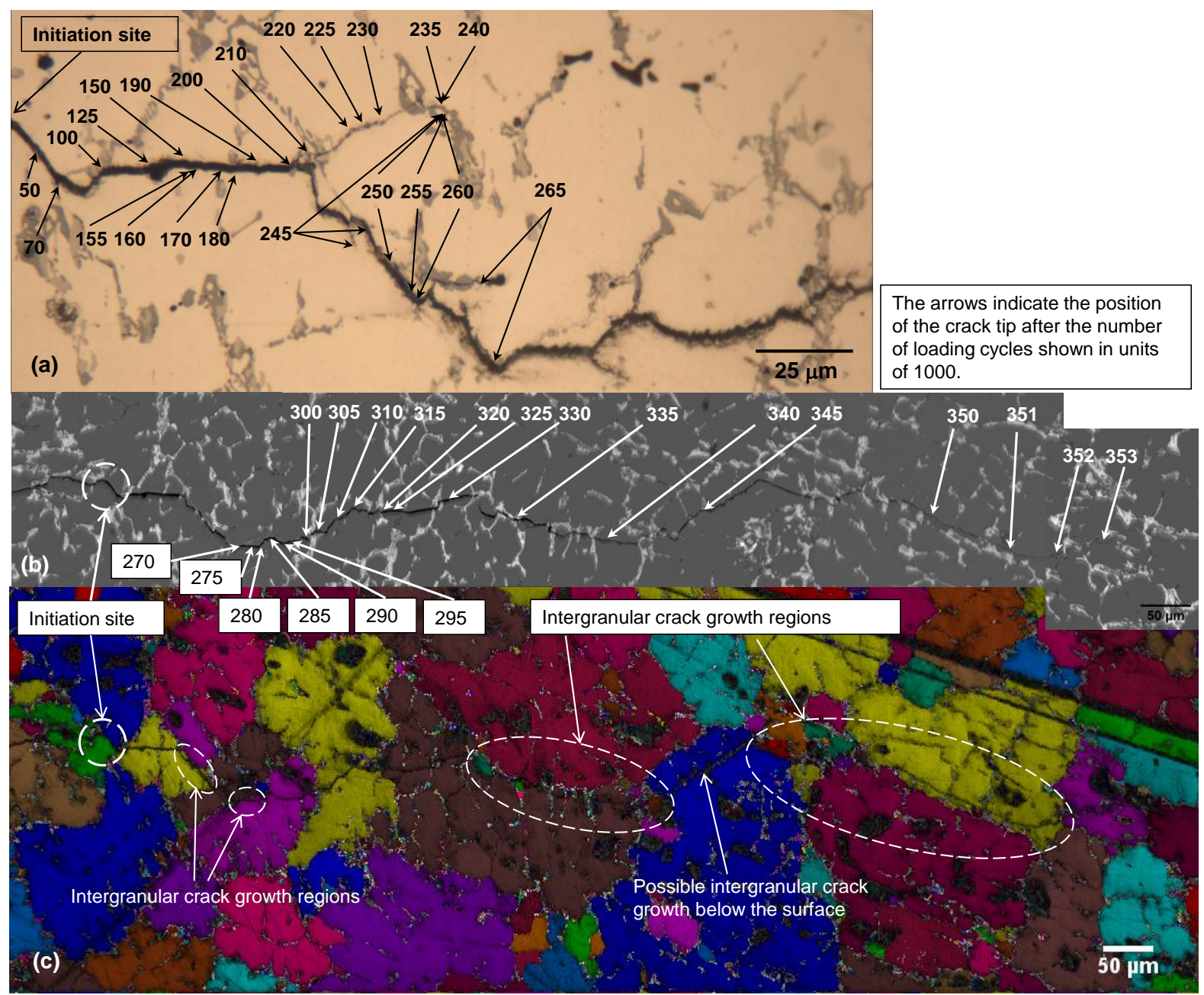

Figure 7 Interaction of crack tip A with intermetallics ( $\&$ b) and grain boundaries (c) for the specimen tested at $\sigma_{\max }=168 \mathrm{MPa}$.

A close examination of the nature of interaction of the short cracks with intermetallics shows that the cracks tend to propagate along the particle/Al matrix interface. However, propagation through fractured particles is also frequently observed but this tends to be at the locations where the particles are either adjoining each other (possibly particle/particle debonding) or where the particle thickness is small (at least on the surface) and aligned normal to the crack plane. This is clearly shown in the representative higher magnification SEM image shown in 11a. The image was taken along crack tip $\mathrm{B}$ from a location with $\Delta \mathrm{K}$ values starting from $\sim 3$ $\mathrm{MPa} \sqrt{ } \mathrm{m}$ at its left hand side.

The micromechanisms of short crack growth for the unhipped alloy repeat specimen was significantly controlled by porosity and exhibited multiple coalescence events due to multiple fatigue crack initiation at pores along the crack profile. In some cases, as many as 7 cracks could be observed to coalesce during crack growth. There were also several cases of crackpore interactions with microcracks emanating from the sharp corners of the pores especially if these corners were oriented towards the nominal crack growth direction (i.e. perpendicular 
to the loading direction). However, there were occasional events in which cracks could still be seen originating from the sharp corners of pores which were oriented parallel to the loading direction. The short cracks were also observed to be both interdendritic and intradendritic but with a higher propensity for interdendritic crack growth and along particle/Al matrix interfaces. The optical image in Figure 11b provides typical examples of some of these observations. EBSD analysis was not carried out for this specimen; it is therefore difficult to ascertain the effect of grain boundaries especially on the pore-crack interactions or the overall crack-microstructure behaviour.
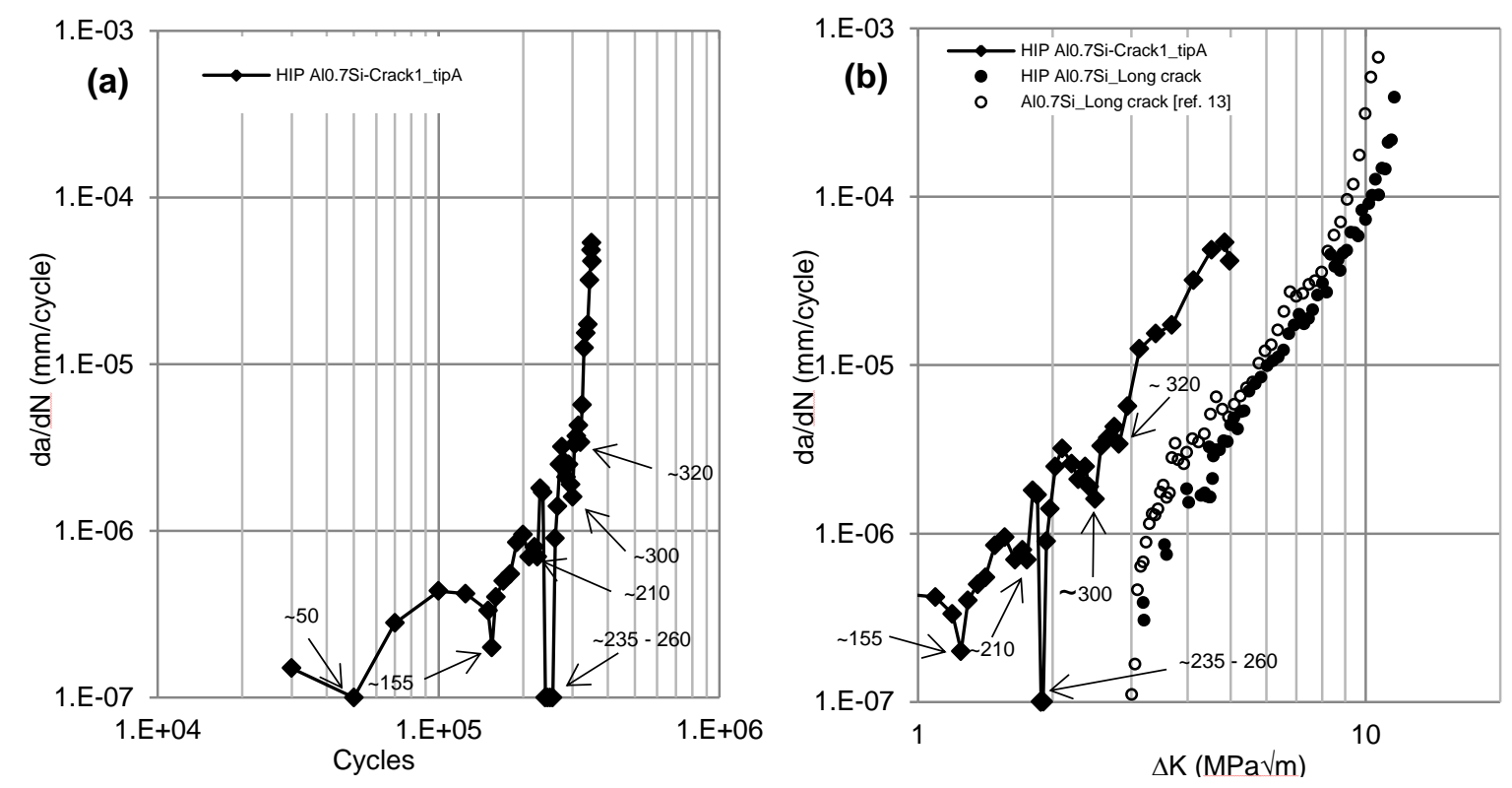

Figure 8 Short crack retardation and arrest events of tip A vs. the corresponding loading cycles in (a) as identified using replicas (shown in Figure 7) and the corresponding $\Delta \mathrm{K}$ in (b).

\section{DISCUSSION}

The short fatigue crack growth data for both hipped and unhipped alloys show classical short crack behaviour which has been the subject of extensive research since it was first reported by Pearson. ${ }^{64}$ The explanations advanced for this behaviour are mainly centred on the invalidity of $\Delta \mathrm{K}$ as a suitable parameter to characterise short crack growth, absence of crack closure and microstructural effects. One significant observation in this work, which is not often reported, is the influence of the applied stress on the short crack growth behaviour. Figure 4a does indeed show increased crack growth rates with increase in the applied stress. This is not expected if the growth rates are characterised in terms of $\Delta \mathrm{K}$. However, the use of $\Delta \mathrm{K}$ to characterise crack growth does implicitly assume small-scale yielding such that the size of the plastic zone at the crack tip is small with respect to the overall crack length ${ }^{65}$. This assumption is mostly violated in short cracks ${ }^{66}$ and the extent of this violation depends on the applied stress and the yield strength of the material, ${ }^{45}$ which affect the plastic zone size. Moreover, loading conditions used in this work result in a plastically deformed layer near the surface of the specimens right from the first loading cycle. This stress dependent global and local crack tip plasticity has been suggested to result in accelerated growth of short cracks $^{45,67,68}$ and can be the cause of the stress dependent results observed in this work for this alloy system. 


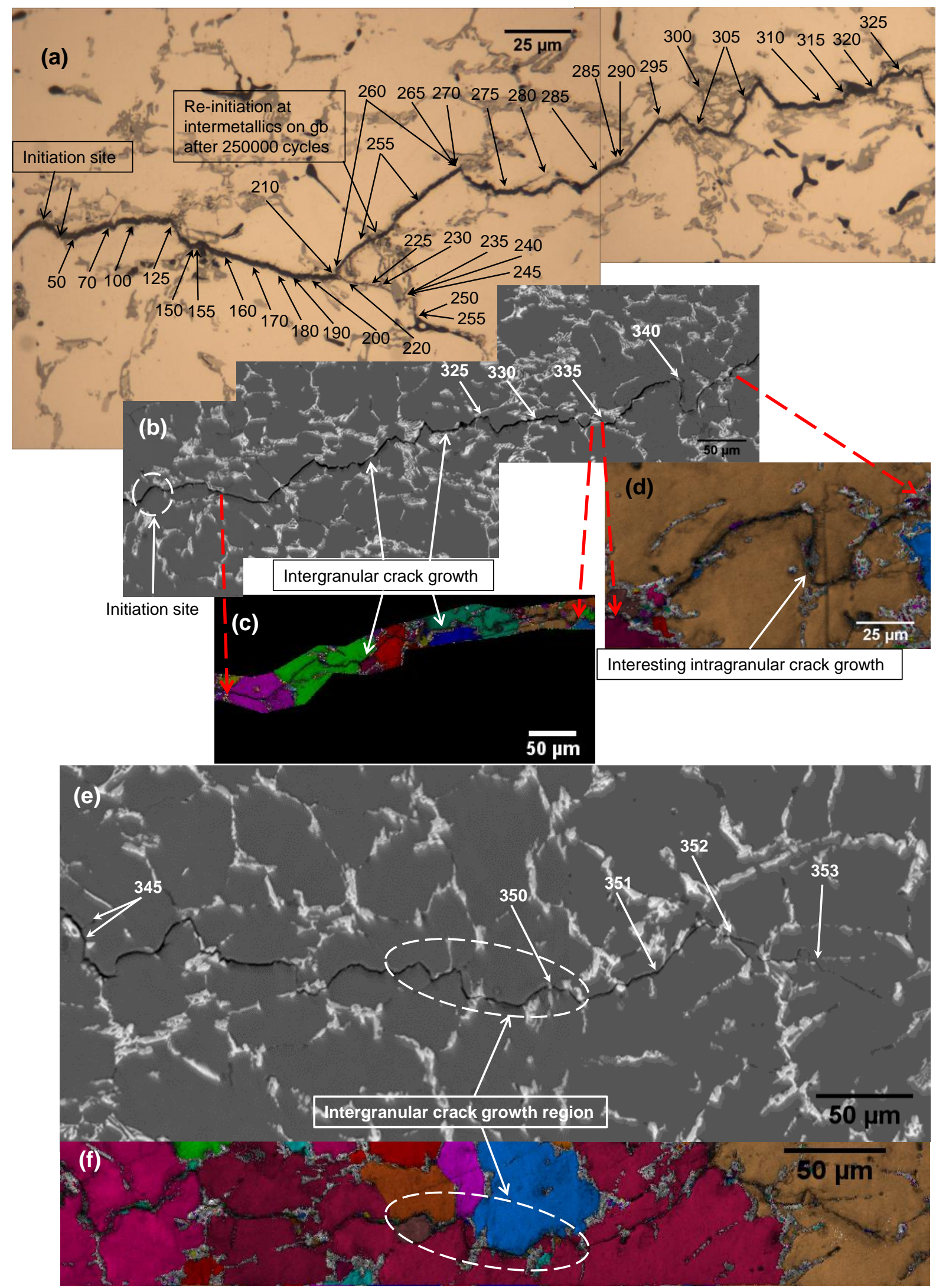

Figure 9 Interaction of tip B of the short crack, shown in Figure 6, with intermetallics and grain boundaries.

The stress dependence of small crack growth has been previously reported by Caton et al. ${ }^{45}$ in a 319-type alloy which varied depending on the heat treatment condition and SDAS. 
Moreover, Plumtree and co-workers ${ }^{42,69}$ have also reported higher short crack growth rates with increased strain amplitude in a squeeze-cast and extruded $\mathrm{Al}-1.4 \% \mathrm{Cu}-1.2 \% \mathrm{Mg}-1.4 \%$ Si-T6 alloy ${ }^{69}$ and in a squeeze-cast A356-T6 type alloy. ${ }^{42}$ Plumtree and Schafer ${ }^{42}$ indeed observed that at high applied strains $(\varepsilon=1 \%)$, cracks grew at faster rates than those at low strains $(\varepsilon=0.36 \%)$. Moreover, growth retardation was observed only for cracks at low strains, which is consistent with the observations in Figures $3 b$ and $4 a$ where crack arrest events disappear at higher applied stresses.
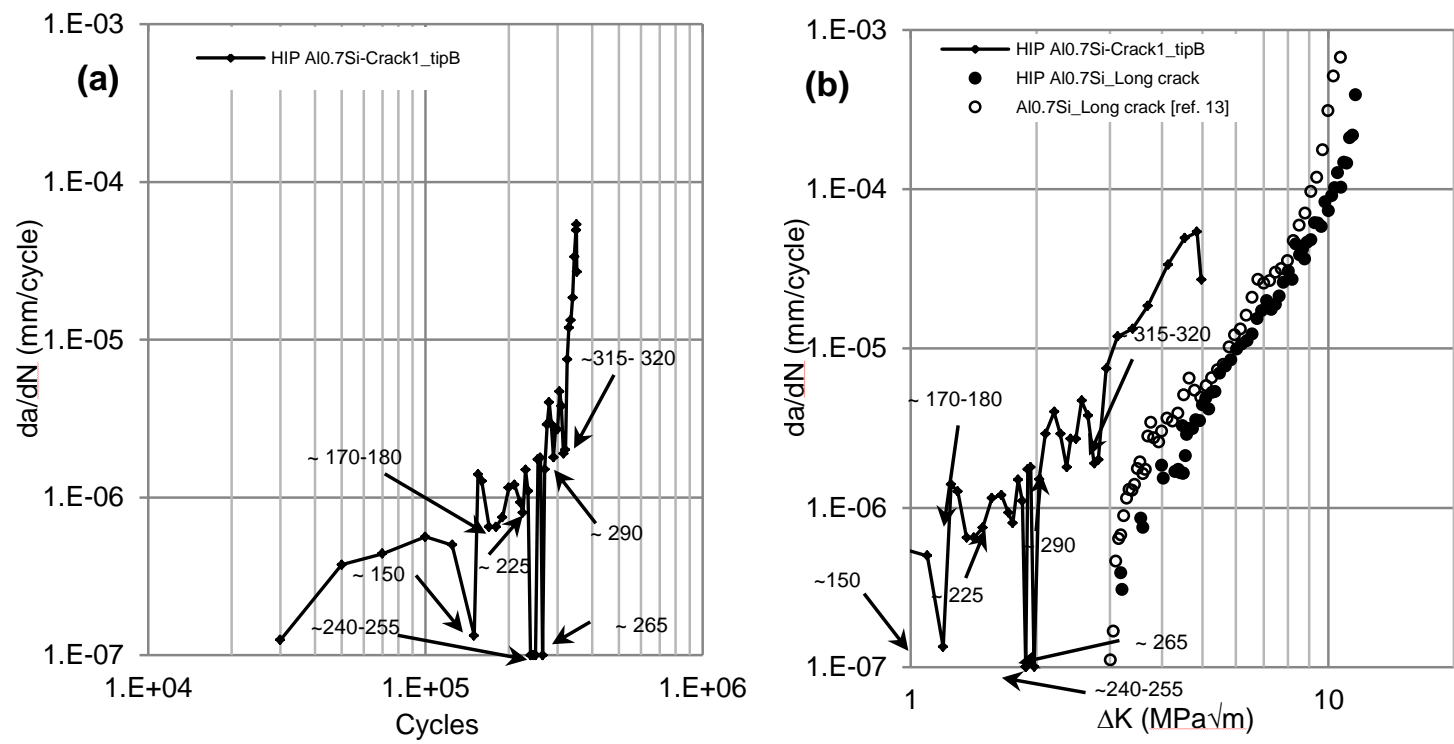

Figure 10 Short crack retardation and arrest events of tip B vs. the corresponding loading cycles in (a) as identified using replicas and shown in Figure 9 and the corresponding $\Delta \mathrm{K}$ in (b).
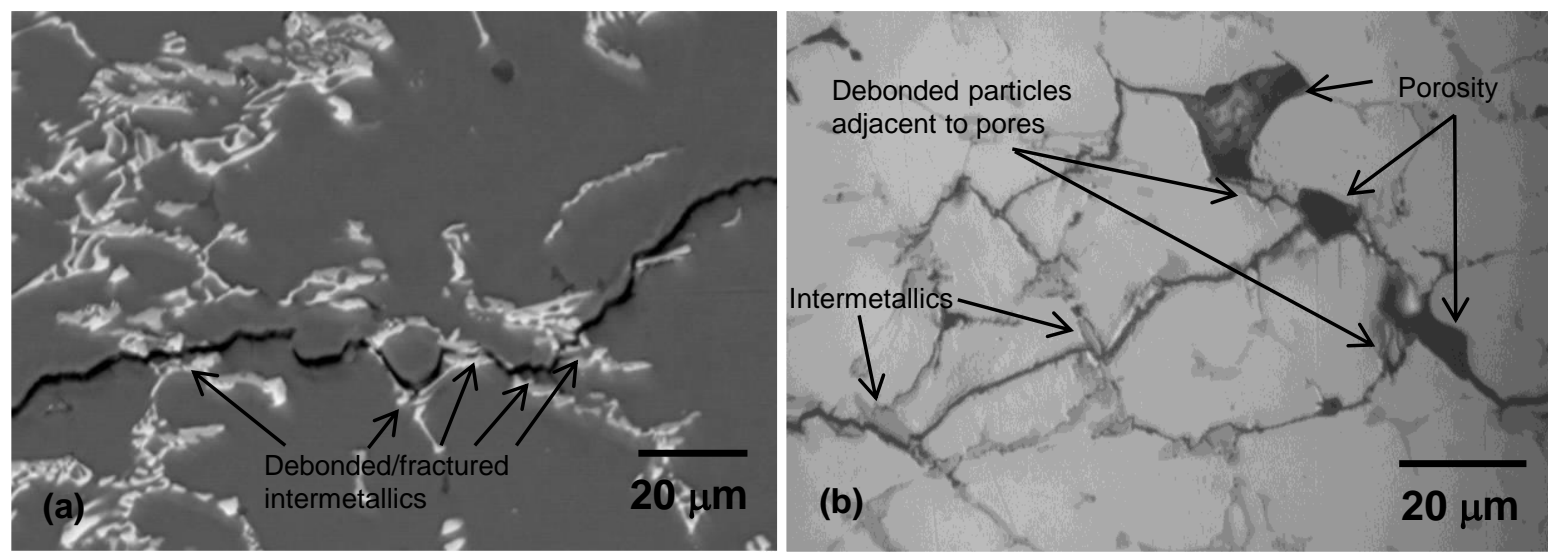

Figure 11 (a) SEM image of a section of crack in Figure 9(b)) showing its interaction with intermetallic particles $(\Delta \mathrm{K} \sim 3 \mathrm{MPa} \sqrt{\mathrm{m}}$ at the left hand side of the image). (b) A typical example of short crack interaction with porosity in the repeat test of the unhipped alloy.

Figure 3a shows that hipping improves the short crack growth resistance of this alloy as reported in Section 3.2. The improved short crack growth behaviour in the hipped alloy can be understood when reviewing the significant crack-pore interactions in the unhipped version as observed in the current study and previous work. ${ }^{13}$ Pore-induced crack growth micromechanisms in this alloy have been discussed in detail by Moffat ${ }^{13}$ and in a recent article by Mbuya et al. ${ }^{70}$ on the effect of hipping on long fatigue cracks. The unhipped alloy has an extensive network of crack-like shrinkage pores throughout its microstructure even 
though the overall pore volume fraction is not that high. These pores are shown to be irregularly shaped with sharp curvature radii using 3D SRCT. ${ }^{70}$ Microcrack formation at these sharp corners is therefore easy due to the high local strains. Indeed, multiple crack initiation from pores was observed in the unhipped alloy both in the current work and in the previous work by Moffat ${ }^{13}$. These microcracks eventually coalesce and therefore the overall crack growth rate is expected to be much faster. Moreover, interaction of each individual crack tips with pores was also observed to be quite frequent as illustrated in Figure 11b. It is believed that microcracks are likely to form ahead of the crack tip at the sharp edges of such pores especially if favourably oriented normal to the loading direction. ${ }^{71,72}$ The advancing crack tip may then be attracted to and accelerated by these microcracks at pores. These processes are much more likely to occur in short cracks than in long cracks and have indeed been inferred from the replica records and the final crack profiles.

Intermetallic particles are also observed to frequently interact with the short cracks in the unhipped alloy but their influence on the overall crack growth behaviour is mostly overshadowed by the influence of pores. However, intermetallics do play a role in determining the local crack growth behaviour at locations remote from pores. Moreover, it is expected that microcrack formation from pores is facilitated by the presence of intermetallics around the pore which serve to raise the local stresses and strains further. ${ }^{39,40}$ Figure $11 \mathrm{~b}$ does indeed show some cases of particle debonding next to pores.

Pore-induced short crack micromechanisms have not been observed in the hipped alloy but crack-particle interactions are indeed quite common as is the case even for the unhipped alloy. In all cases, the crack is seen to propagate in the interdendritic regions as well as within the primary Al dendrites (intradendritic). This is consistent with previous observations. ${ }^{13}$ However, observations suggest that interdendritic crack growth is preferred in both the hipped and unhipped versions of the alloy as shown in Figures 7, 9 and 11a. The suggestion by Moffat ${ }^{13}$ that the cracks may have a propensity for intradendritic crack growth when remote from pores is not consistent with observations in the hipped alloy where porosity effects do not apply. Moreover, another key observation not reported previously for this alloy is that cracks preferentially propagate through the intermetallic/Al interfaces whenever they encounter such particles. This was also observed to occur in the hipped version of the 6.9 wt.\% Si alloy shown in Table $1 .{ }^{53}$ Although propagation through fractured particles is also observed, this is less frequent and mostly confined to thin favourably oriented particles (parallel to the loading direction). This result is consistent with observations of a precipitate free zone around intermetallic particles observed in aluminium alloys as discussed by Starink. ${ }^{46}$ The presence of a precipitate free zone means that the region around these particles is softer than the bulk Al matrix. Coupled with higher local stresses due to load transfer effects of the intermetallics, interface failure is expected to preferentially occur. Particle fracture can and will indeed occur in cases where the particle size and orientation are favourable for efficient load transfer as discussed in detail by Starink. ${ }^{46}$

The role of grain boundaries must however be considered when interpreting crackmicrostructure interactions and their impact on growth rates. Figures 7 and 9 do indeed show that most of what may be considered from simple optical and SEM to be interdendritic crack growth is in fact along grain boundaries. As such, the interface decohesion along intermetallic particles located at the grain boundaries could also be augmented by the precipitate free zones often observed at the grain boundary as previously reported by Mulvihill and Beevers. ${ }^{73}$ This also suggests that cracks are likely to preferentially propagate along grain boundaries since they provide a weaker path. The exception is when cracking in 
the Al matrix is facilitated by, for example, slip band formation due to accumulation of localised plastic strain within the grain that may be intensified by the presence of intermetallics.

A crack will therefore be expected to retard or arrest at a grain boundary as it is forced to deflect and grow along the boundary. It will continue to grow in this manner until conditions are favourable for it to enter into a new grain or it is unfavourable for it to continue along the boundary. The latter case is possible if it encounters a grain boundary triple point. This is consistent with observations in Figures 7 to 10, which show that crack growth retardations occur when the crack interacts with a grain boundary. Similar grain boundary crack growth retardations have previously been reported by Mulvihill and Beevers ${ }^{73}$ for an $\mathrm{Al}-4.5 \% \mathrm{Cu}$ alloy. Several other researchers ${ }^{39,47}$ have observed similar grain boundary effects on the short crack growth behaviour in less microstructurally complex A356 type alloys.

Crack growth retardation and arrest events are also observed at intermetallic particles in the hipped alloy. Crack retardation at particles may be partly associated with forced deflections as the crack seeks to propagate through the weak interfaces and as such will depend on the particle size and orientation relative to the plane of the crack tip. Intact (uncracked) particles oriented normal to the crack plane are expected to be effective barriers and the crack will be forced to deflect sharply in order to bypass the particle or continue to be arrested until the particle eventually fails. On the other hand, particles ahead of the crack tip which are oriented parallel to the crack plane are expected to offer least resistance along their interface. However, previously failed particles (debonded or fractured) situated ahead of the crack tip will naturally provide the weakest path. Some of these possible crack-particle interactions are discussed in detail in reference. ${ }^{13}$ Whether a particle acts as an effective barrier or a weak path ultimately depends on its load carrying capacity which depends on its size and orientation and whether it is already cracked or debonded by the time the crack interacts with it.

\section{CONCLUSIONS}

The influence of intermetallic phases and grain boundaries on the short fatigue crack growth behavior of a hipped cast $\mathrm{Al}-4 \mathrm{Cu}-3 \mathrm{Ni}-0.7 \mathrm{Si}$ piston alloy was investigated. The following conclusions can be drawn from the results obtained in this work:

1. Hipping resulted in improved fatigue crack growth resistance which is attributed to the absence of pore-induced crack growth acceleration.

2. Short fatigue crack growth was frequently observed to retard at intermetallic particles and grain boundaries in the hipped A10.7Si alloy. Crack retardation at particles can be associated with the size and orientation of particles. Large uncracked particles oriented normal to the crack plane are effective barriers at which the crack will be forced to deflect sharply in order to bypass it or continue to be arrested until the particle eventually fails.

3. The short crack growth was observed to be interdendritic and intradendritic as well as intergranular and transgranular in the hipped Al0.7Si alloy. However, there was a higher propensity for interdendritic and intergranular crack growth in this alloy.

4. Finally, short cracks were observed to grow preferentially along the particle/Al interface whenever they encountered such particles. This is attributed to the higher local stresses due to load transfer effects and the presence of a precipitate free zone around intermetallic particles observed in aluminium alloys thus weakening the interface. Short crack propagation through fractured particles was also observed but 
this was less frequent and mostly confined to thin particles oriented parallel to the loading direction.

\section{Acknowledgements}

The first author acknowledges the Faculty of Engineering and the Environment of the University of Southampton and the University of Nairobi for their financial support when this work was carried out. Dr. Katherine Soady is also acknowledged for her assistance with the FE calculations to establish the local stress states. Finally, the authors would like to thank Professor Ian Sinclair for fruitful discussions that helped to improve the quality of this work.

\section{REFERENCES}

1. Edwards, W.M. (2002) Microstructural and mechanical property modelling for the processing of $\mathrm{Al}-\mathrm{Si}$ Alloys. $\mathrm{PhD}$ Thesis, Institute of Polymer Technology and Materials Engineering, Loughborough University.

2. Edwards, W. M. , Thomson, R. C., Barnes, S. J. and Barnes, S.I. (2002) Development of near-eutectic Al-Si casting alloys for piston applications. Mater. Sci. Forum, 396402, 625-630.

3. Mielke, S.G., Steffens, T., Beer, S. and Henning, W. (1998) New aluminum piston alloy with increased fatigue strength at high temperatures. SAE Technical Paper 980687, doi:10.4271/980687.

4. Zhang, Q., Zuo, Z. and Liu, J. (2012) High-temperature low-cycle fatigue behaviour of a cast Al-12Si-CuNiMg alloy. Fatigue Fract. Eng. Mater. Struct., 36, 623-630

5. Lee, J.A. and Chen, P.-S. (2005) High strength aluminum alloy for high temperature applications. US Patent, No. US 6918970 B2.

6. Barnes, S. and Lades, K. (2002) The evolution of aluminium based piston alloys for direct injection diesel engines. SAE Technical Paper 2002-01-0493, doi:10.4271/2002-01-0493.

7. Yang, Y., Yu, K., Li, Y., Zhao, D. and Liu, X. (2012) Evolution of nickel-rich phases in $\mathrm{Al}-\mathrm{Si}-\mathrm{Cu}-\mathrm{Ni}-\mathrm{Mg}$ piston alloys with different $\mathrm{Cu}$ additions, Mater. Design, 33, 220225.

8. Cho, Y.H., Im, Y.-R., Kwon, S.-W. and Lee, H.C. (2003) The effect of alloying elements on the microstructure and mechanical properties of Al-12Si cast alloys. Mater. Sci. Forum, 426-432, 339-344.

9. Yang, Y., Li, Y., Wu, D., Zhao, D. and Liu, X. (2011) Effect of existing form of alloying elements on the microhardness of Al-Si-Cu-Ni-Mg piston alloy. Mater. Sci. Eng. A, 528, 5723-5728

10. Reichstein, S., Konrad, P., Kenningley, S. and Dornenburg, F. T. H. (2008) Materials modification: Piston materials for high stress and temperature conditions. ATZ Autotechnology, 8, 42-47.

11. Myers, M. R. and Hurd, N. J. (1990) The interaction of creep and fatigue in an aluminum-silicon alloy. In: High temperature fracture mechanisms and mechanics, edited by Bensussan, P. Mechanical Engineering Publications, London, 147-162.

12. Floweday, G., Petrov, S., Tait, R. B. and Press, J. (2011) Thermo-mechanical fatigue damage and failure of modern high performance diesel pistons. Eng. Fail. Anal., 18, 1664-1674.

13. Moffat, A.J. (2007) Micromechanistic analysis of fatigue in aluminium silicon casting alloys. PhD Thesis, School of Engineering Sciences, University of Southampton. 
14. Zhang, Q., Zuo, Z. and Liu, J. (2013) Stepped-isothermal fatigue analysis of engine piston. Fatigue Fract. Eng. Mater. Struct., 37, 417-426.

15. Moffat, A,J., Mellor, B.G., Chen, C.L., Thomson, R.C. and Reed, P.A.S. (2006) Microstructure analysis of fatigue initiation in Al-Si casting alloys. Mater. Sci. Forum, 519-521, 1083-1088.

16. Zhang, G., Zhang, J., Li, B. and Cai, W. (2013) Double-stage hardening behavior and fracture characteristics of a heavily alloyed Al-Si piston alloy during low-cycle fatigue loading. Mater. Sci. Eng. A, 561, 26-33.

17. Chen, C. L., (2006) Characterisation of intermetallic phases in multicomponent Al-Si alloys for piston applications. PhD Thesis, IPTME, Loughborough University, UK.

18. Moffat, A.J., Barnes, S., Mellor, B.G. and Reed, P.A.S. (2005) The effect of silicon content on long crack fatigue behaviour of aluminium-silicon piston alloys at elevated temperature. Int. J. Fatigue, 27, 1564-1570.

19. Joyce, M.R., Styles, C.M. and Reed, P.A.S. (2003) Elevated temperature short crack fatigue behaviour in near eutectic Al-Si alloys. Int. J. Fatigue, 25, 863-869.

20. Rooy, E. L. (1988) Aluminum and Aluminum Alloys. ASM Handbook, Vol. 15: Casting, ASM International, Materials Park, Ohio, USA.

21. Rakhmonov, J., Timelli, G. and Bonollo, F. (2016), The effect of transition elements on high-temperature mechanical properties of Al-Si foundry alloys - A review . Adv. Eng. Mater. 18, 1096-1105. doi:10.1002/adem.201500468.

22. Javidani, M. and Larouche, D. (2014) Application of cast Al-Si alloys in internal combustion engine components, Int. Mater. Rev., 59, 132-158.

23. Chen, C. L., West, G. D. and Thomson, R. C. (2006) Characterisation of intermetallic phases in multicomponent Al-Si casting alloys for engineering applications. Mater. Sci. Forum, 519-521, 359-364.

24. Asghar, Z., Requena, G. and Boller, E. (2011) Three-dimensional rigid multiphase networks providing high-temperature strength to cast AlSi10Cu5Ni1-2 piston alloys. Acta Mater., 59, 6420-6432.

25. Daykin, C.R.S. (1998) Microstructural modelling of commercial aluminium-silicon alloys for piston design, PhD thesis, Department of Materials Science and Metallurgy, Cambridge, Magdalene College, Cambridge.

26. Cho, Y.-H., Joo, D.-H., Kim, C.-H. and Lee, C.-C (2006) The effect of alloy addition on the high temperature properties of over-aged Al-Si (CuNiMg) cast alloys. Mater. Sci. Forum, 519-521, 461-466.

27. Mbuya, T. O., Sinclair, I., Moffat, A. J., Reed, P. A. S. (2011) Analysis of fatigue crack initiation and S-N response of model cast aluminium piston alloys, Mater. Sci. Eng. A, 528, 7331-7340.

28. Chen, C.L., Richter, A. and Thomson, R.C. (2009) Mechanical properties of intermetallic phases in multi-component $\mathrm{Al}-\mathrm{Si}$ alloys using nanoindentation. Intermetallics, 17, 634-641.

29. Gall, K., Yang, N., Horstemeyer, M., McDowell, D.L. and Fan, J. (2000) The influence of modified intermetallics and Si particles on fatigue crack paths in a cast A356 Al alloy. Fatigue Fract. Eng. Mater. Struct. 23, 159-172.

30. Wang, Q., Apelian, D. and Lados, D. (2001) Fatigue behavior of A356-T6 aluminum cast alloys. Part I. Effect of casting defects. J. Light Met., 1, 73-84.

31. Gao, Y.X., Yi, J.Z., Lee, P.D. and Lindley, T.C. (2004) The effect of porosity on the fatigue life of cast aluminium-silicon alloys. Fatigue Fract. Eng. Mater. Struct. 27, 559-570. 
32. Couper, M.J., Neeson, A.E. and J.R. Griffiths, J.R. (1990) Casting defects and the fatigue behaviour of an aluminium casting alloy. Fatigue Fract. Eng. Mater. Struct., 13, 213-227.

33. Wang, Q.G., Crepeau, P.N., Davidson, C.J. and Griffiths, J.R. (2006) Oxide films, pores and fatigue lives of cast aluminum alloys. Metall. Mater. Trans. B, 37B, 887895.

34. Zhang, B., Poirier, D.R. and Chen, W. (1999) Microstructural effects on high-cycle fatigue-crack initiation in A356. 2 casting alloy. Metall. Mater. Trans. A, 30, 26592666.

35. Jiang, H., Bowen, P. and Knott, J.F. (1999) Fatigue performance of a cast aluminium alloy Al-7Si-Mg with surface defects. J. Mater. Sci., 34, 719-725.

36. Ting, J.C. and F.V. Lawrence Jr, (1993) Modeling the long life fatigue behavior of a cast aluminum alloy. Fatigue Fract. Eng. Mater. Struct., 16, 631-647.

37. Mayer, H.R., Lipowsky, H., Papakyriacou, M., Rösch, R., Stich, A., Stanzl-Tschegg, S. E. (1999) Application of ultrasound for fatigue testing of lightweight alloys. Fatigue Fract. Eng. Mater. Struct., 22, 591-599.

38. Fan, J., McDowell, D.L., Gall, K. and Horstemeyer, M., (2003) Cyclic plasticity at pores and inclusions in cast Al-Si alloys. Eng. Fract. Mech., 70, 1281-1302.

39. Buffiere, J. Y., Savelli, S., Jouneau, P. H., Maire, E. and Fougeres, R. (2001) Experimental study of porosity and its relation to fatigue mechanisms of model AlSi7-Mg0.3 cast Al alloys. Mater. Sci. Eng. A, 316, 115-126.

40. Gao, Y.X., Yi, J.Z., Lee, P.D. and Lindley, T.C. (2004) A micro-cell model of the effect of microstructure and defects on fatigue resistance in cast aluminum alloys. Acta Mater, 52, 5435-5449.

41. Shiozawa, K., Tohda,Y. and Sun, S.M. (1997) Crack initiation and small fatigue crack growth behaviour of squeeze-cast Al-Si aluminium alloys. Fatigue Fract. Eng. Mater. Struct., 20, 237-247.

42. Plumtree, A. and Schafer, S. (1986) Initiation and Short Crack Behaviour in Aluminium Alloy Castings. in The Behaviour of Short Fatigue Cracks, Edited by Miller, J. K. and De los Rios, E. R., Mechanical Engineering Publications, London, 215-227.

43. Yi, J.Z., Gao, Y.X., Lee, P.D. and Lindley, T.C. (2006) Microstructure-based fatigue life prediction for cast A356-T6 aluminum-silicon alloys. Metall. Mater. Trans. B, 37, 301-311.

44. Yi, J.Z., Gao, Y.X., Lee, P.D. and Lindley, T.C. (2004) Effect of Fe-content on fatigue crack initiation and propagation in a cast aluminum-silicon alloy (A356-T6). Mater. Sci. Eng. A,. 386, 396-407.

45. Caton, M. J., Wayne Jones, J., Boileau, J. M. and Allison, J. E. (1999) The effect of solidification rate on the growth of small fatigue cracks in a cast 319-type aluminum alloy. Metall. Mater. Trans. A, 30, 3055-3068.

46. Starink, M.J., (2005) Reduced fracturing of intermetallic particles during crack propagation in age hardening Al-based alloys due to PFZs. Mater. Sci. Eng. A, 390, 260-264.

47. Ludwig W., Buffiere, J.Y., Savelli S. and Cloetens P. (2003) Study of the interaction of a short fatigue crack with grain boundaries in a cast Al alloy using X-ray microtomography. Acta. Mater., 51, 585-598.

48. Han, S.W., Kumai, S. and Sato, A. (2002) Effects of solidification structure on short fatigue crack growth in $\mathrm{Al}-7 \% \mathrm{Si}-0.4 \% \mathrm{Mg}$ alloy castings. Mater. Sci. Eng. A, 332, 56-63. 
49. Ferrie, E., Buffière, J. and Ludwig, W. (2005) 3D characterisation of the nucleation of a short fatigue crack at a pore in a cast $\mathrm{Al}$ alloy using high resolution synchrotron microtomography. Int. J. Fatigue, 27, 1215-1220.

50. Hayat, N., Toda, H., Kobayashi, T. and Wade, N. (2002) Experimental investigations of fatigue characteristics of $\mathrm{AC} 4 \mathrm{CH}$ cast aluminum alloys fabricated through rheocast and squeeze cast methods. Mater. Sci. Forum, 396-402, 1353-1358.

51. Styles, C. M. and Reed, P. A. S. (2000) Fatigue of an Al-Si gravity die casting alloy. Mater. Sci. Forum, 331-337, 1457-1462.

52. Moffat, A.J., Mellor, B. G., Sinclair, I and Reed P. A. S. (2009) Short crack and near threshold fatigue behaviour of $\mathrm{Al}-\mathrm{Si}$ casting alloys. In: The $12^{\text {th }}$ International Conference on Fracture, 12-17 July, Ottawa, Ontario, Canada, Vol. 4, 3081-3090.

53. Mbuya, T. O. and Reed, P. A. S. (2014) Micromechanisms of short fatigue crack growth in an Al-Si piston alloy. Mater. Sci. Eng. A, 612, 302-309.

54. Reichstein, S., Weiss, R., Kenningley, S., Lades, K., Konrad, P. and Doernenburg, F. T. H. (2007) High-performance cast aluminum pistons for highly efficient diesel engines. SAE Technical Paper 2007-01-1438, doi:10.4271/2007-01-1438.

55. Mbuya, T.O. (2011) Analysis of microstructure and fatigue micromechanisms in cast aluminium piston alloys. PhD Thesis, Faculty of Engineering and the Environment, School of Engineering Sciences, University of Southampton, UK.

56. Underwood, E. E. (1970) Quantitative Stereology. Addison-Wesley Publishing Company, Reading, MA, USA.

57. Swain, M.H. (1992) Monitoring small-crack growth by the replication method. in Small-Crack Test Methods, ASTM STP1149, 34-56.

58. Scott, P. M. and Thorpe, T.W. (1981) A critical review of crack tip stress intensity factors for semi-elliptic cracks. Fatigue Fract. Eng. Mater. Struct., 4, 291-309.

59. Staley, Jr. J. T., Tiryakioglu, M. and Campbell, J. (2007) The effect of increased HIP temperatures on bifilms and tensile properties of A206-T71 aluminum castings. Mater. Sci. Eng. A, 460, 324-334.

60. Shivkumar, S., Ricci, S., Steenhoff, B. and Sigworth, G. (1989) An experimental study to optimize the heat treatment of A356 alloy. AFS Trans., 97, 791-810.

61. Sjölander, E. and Seifeddine, S. (2010) The heat treatment of Al-Si-Cu-Mg casting alloys. J. Mater. Process. Technol., 210, 1249-1259.

62. Chaudhury, S. K. and Apelian, D. (2006) Fluidized bed heat treatment of cast Al-SiCu-Mg alloys. Metall. Mater. Trans. A, 37, 2295-2311.

63. Samuel, A. M., Gauthier, J. and Samuel, F.H. (1996) Microstructural aspects of the dissolution and melting of $\mathrm{Al}_{2} \mathrm{Cu}$ phase in $\mathrm{Al}-\mathrm{Si}$ alloys during solution heat treatment. Metall. Mater. Trans. A, 27, 1785-1798.

64. Pearson, S. (1975) Initiation of fatigue cracks in commercial aluminium alloys and the subsequent propagation of very short cracks. Eng. Fract. Mech., 7, 235-247.

65. Suresh, S. Fatigue of materials, 2nd ed. Cambridge: Cambridge University Press, 1998.

66. Lankford, J., Davidson, D. L. and Chan, K. S. (1984) The influence of crack tip plasticity in the growth of small fatigue cracks. Metall. Mater. Trans. A, 15, 15791588.

67. Hudak, S. J. and Chan, K. S. (1986) In Search of a driving force to characterize the kinetics of small crack growth, In: Small Fatigue Cracks, edited by Ritchie, R. O. and Lankford, J. The Metallurgical Society, Santa Barbara, California, 379-403.

68. Edwards, L. and Zhang, Y. H. (1994) Investigation of small fatigue cracks - I. Plastic deformation associated with small fatigue cracks. Acta Metall. et Mater., 42, 14131421. 
69. Plumtree, A. and O'Connor, B. P. D. (1993) Influence of microstructure on short fatigue crack growth. Fatigue Fract. Eng. Mater. Struct., 14, 171-184.

70. Mbuya, T. O., Sinclair, I., Moffat, A. J. and Reed, P. A. S. Micromechanisms of fatigue crack growth in cast aluminium piston alloys. Int. J. Fatigue, 42, 227-237.

71. Rading, G. O., Li, J. and Berry, J. T. (1994) Fatigue crack growth in cast Al-Cu alloy A206 with different levels of porosity. AFS Trans., 102, 57-61

72. Chan, K., Jones, P. and Wang, Q. (2003) Fatigue crack growth and fracture paths in sand cast B319 and A356 aluminum alloys. Mater. Sci. Eng. A, 341, 18-34.

73. Mulvihill, P. and Beevers, C. J. (1986) The initiation and growth of intergranularly initiated short fatigue cracks in an aluminium 4.5 per cent copper alloy. in The Behaviour of Short Fatigue Cracks, Edited by Miller, J. K. and De los Rios, E. R., Mechanical Engineering Publications, London, 203-212. 